\title{
How Creationism Supports Kripke's Vichianism on Fiction
}

\section{Alberto Voltolini}

\section{Introduction}

In this paper, I want to show that a reasonable thesis on truth in fiction, Fictional Vichianism (FV) - according to which fictional truths are true because they are stipulated to be true - can be positively endorsed if one grounds Kripke's justification for (FV), that traces back to the idea that names used in fiction never refer to concrete real individuals, into a creationist position on fictional entities that allows for a distinction between the pretending and the characterizing use of fiction-involving sentences. Thus, sticking to $(\mathrm{FV})$ provides a reason for a metaphysically moderate ontological realism on fictional entities.

\section{Fictional Vichianism}

As is well known, in his masterpiece The New Science (17301744/1948), the Italian 18th-century philosopher Giovanni Battista Vico defended the thesis that verum ipsum factum, namely, the thesis that truth is the same as historical facts.

Vico's thesis is normally meant as a claim in epistemology: given a Cartesian form of scepticism about the outer world, the only things which can be known to be true are those which are made by humans. Yet by itself, one may well mean it as a claim in ontology: the only things which are true are those which concern lato sensu mind-dependent 
things, as things which are made by humans are; in a nutshell, the only things which are true are historical facts.

Even so, the thesis is quite controversial, for it relies on an analogously controversial ontological reading of the aforementioned Cartesian scepticism, according to which as regards ultimately mindindependent things, there simply are no facts of the matter. However, it seems that there is at least a region of reality in which things are true for they are made by humans: that is, which concern effectively minddependent things, as artefacts are: in a nutshell, artefactual facts. In particular, this is the case with fictional truths, which are a kind of artefactual facts.

In this respect, once one switches from an ontological consideration of truth as factuality to a linguistic consideration of truth as a property of (some interpreted) sentences, one may well envisage a Vichianist position on fiction, Fictional Vichianism:

(FV) fictional truths are true because they are stipulated to be true, not because they are made true by an external reality. ${ }^{1}$

(FV) seems reasonable enough. For fiction precisely seems to be a case in which whatever is true or false depends on us, in particular on what a certain author decides by narrating a certain story in a certain way. In point of fact, if we take a sentence like:

Holmes is a detective

it seems that there is no reason as to why this sentence is true, but for the fact that Conan Doyle decided to so characterize Holmes in his narration: if it is true, then it has been so stipulated. Of course, Doyle might have written that Holmes was a folksinger or a politician; in such a case (1) would be false, for Doyle would have simply conjured up a completely different story. As Deutsch (2000) puts it, a fictional story is something made up. Conversely, if something apparently involving

\footnotetext{
${ }^{1}$ For a clear formulation of (FV), $c f$. the following passage: "as far as literally fiction is concerned, the author is the authority. There is nothing else-e.g. reality, or other texts - towards which he is responsible. [...] To read a text as a literary fiction is to decide not to look for any other justification over and above the text itself for the truth of the statements we read" (Santambrogio, 1992, p. 302; my translation).
} 
fiction has not been decided by an author or it cannot be entailed either by her decisions or by the environment her decisions have contributed to sketch, there is no way of assessing it as true, or as false for that matters. Put alternatively, any fiction $F$ is ontologically incomplete, in the sense that for some pairs of states of affairs $S$ and its complement not- $S, F$ does not contain either. In this respect, fiction behaves in the very same way as mathematics does for constructivists: there is no fact of the matter as to whether a mathematical series, or a numerical progression, proceeds in a certain way or not, until no calculation on that concern has been performed. As Wittgenstein brilliantly put once:

But what are you saying if you say that one thing is clear: either one will come on $\varphi$ in the infinite expansion [of $\pi$ ], or one will not?

[...] What if someone were to reply to a question: So far there is no such thing as an answer to this question?

So, e.g. the poet might reply when asked whether the hero of his poem has a sister or not - when, that is, he has not decided yet anything about it. (Wittgenstein, 1978, V§9).

\section{Is there a way of grounding Fictional Vichianism?}

Intuitive as it may seem, one may well wonder whether (FV) is correct. Could not one entertain the apparently counterintuitive idea that what a piece of fiction says is true for things so stand in the world that piece of fiction contributes to select? Moreover, is this idea really so counterintuitive? Consider:

The Earth is round.

Definitely, (2) is not only a real, but also a fictional truth, for instance as far as the Holmes stories are concerned. Yet (2) is not explicitly said by Doyle, moreover, it cannot be inferred by what Doyle explicitly said, nor by the environment that what he explicitly said contributes to sketch-a 19th-century Britain, say. One would thus be tempted to say that (2) is true for this is how things behave in the worlds of Doyle's stories, not 
because of any (explicit or implicit) stipulation on Doyle's part. Thus, it seems that (FV) stands in need of a justification. But what can justify it?

In (1980), Kripke seems to espouse (FV). A sentence like (1) does not come out to be true for it turns out that in the outer reality there is a Holmes-like detective. Even if by sheer coincidence it turned out that in the outer reality things behave as in the Holmes stories, says Kripke, this does not make those stories true.

According to Kripke, there precisely is a specific reason as to why (FV) is correct. Since in general truth depends on reference and in particular a fiction-involving name does not refer to any real life individual, however similar to the corresponding personage the relevant fiction narrates of, then a fiction-involving sentence containing that name is not made true by what happens to that individual. In particular, "Holmes" does not refer to any Holmes-like concrete real detective; thus, (1) is not made true by what happens to that detective. In Kripke's own words:

The mere discovery that there was indeed a detective with exploits like those of Sherlock Holmes would not show that Conan Doyle was writing about this man; it is theoretically possible, though in practice fantastically unlikely, that Doyle was writing pure fiction with only a coincidental resemblance to the actual man (1980, p. 157).

From Kripke's way of putting things, two consequences apparently follow. On the one hand, it may turn out that fictional truths are more than it prima facie seems, for often we erroneously believe that we are referring to a concrete real individual, while in actual fact we are makebelievedly referring to something. Typically, this happens in the case of myths - by means of the name "Santa" we don't refer to a concrete real man, say, an ancient Italian bishop from Bari, for the referential chain that links contemporary uses of that name does not lead back to that man-, or of fake stories - by means of the name "King Arthur", pace Geoffrey of Monmouth, the author of the Historia Regum Britanniae, we do not refer to a 5th-century Romano-Briton conductor, for the referential chain that links contemporary uses of that name does not lead back to that man (if there were any). All this amounts to the relatively 
trivial discovery that not all fiction is intentional. Yet on the other hand, at least some fiction is such. As a matter of fact, it cannot turn out that what we take as a fictional truth is a real one. For it cannot turn out that we erroneously believe that we are make-believedly referring to something, while we are actually referring to a typically concrete real individual. (1) is a case in point. It cannot turn out that (1) is a real rather than a fictional truth, for it cannot turn out that, pace Doyle's opposite convictions, by "Holmes" he was referring to a concrete real individual.

Now, the first consequence is hardly contestable-witness the discovery any Western child happens to make that Santa does not exist, is no concrete real individual. Yet the second consequence sounds rather perplexing. If we may discover that a tale we took to be real is a fictional one, hence that a certain referential chain for a name does not end in a concrete real individual but, to use Donnellan (1974)'s terminology, it ends in a block - $c f$. the "Santa"-myth, or the Historia Regum Britanniae - why can't we make the opposite discovery that a tale we took to be fictional is a real one, hence that a certain causal chain for a name does not end in a block but in a concrete real individual? Consider e.g. the "Vinland" tale. For a long while, people have believed that Erik the Red's report concerning a land named "Vinland" was a fictional tale on an imaginary land. Yet recent archaeological discoveries have revealed traces of Viking villages on the Eastern side of the Canadian coast. This has shown that "Vinland" was not used by Erik and his companions as a name for an imaginary land, but was simply those Vikings' name for (at least a part of) Northern America. Thus, the "Vinland" tale was not fictional at all.

The morale of this doubt is that there is no way of showing that what is taken to be an "empty" referential chain, that is, a chain ending in a block, is really such. If this is the case, there is no way of proving that the corresponding truth which prima facie is such for it has been stipulated as such has really such a character. Hence, (FV) is threatened.

On behalf of Kripke's, one may reply to this doubt as follows. Of course we can mistake a real tale for a fictional one, insofar as we can mistake a "full" referential chain for an "empty" one, as in the case of "Vinland". Yet it remains that, once we establish that a tale has been made up by a certain author, it cannot turn out that that tale is real, 
insofar as the referential chain that author inaugurates definitely is an "empty" one. As is the case with the "Holmes" tales. We know for sure that those tales are not reports about a concrete real individual, for they were entirely made up by Doyle. This in turn depends on the fact that the name "Holmes" did not name one such individual, for it was altogether coined by Doyle in writing down the story he was creating. Put alternatively, it may well turn out that we were wrong on the fictional character of the "Vinland" tale. Yet it cannot turn out that we were wrong on the fictional character of the "Holmes" tales. For, while even the author of the "Vinland" tale may be mistaken on the origins of the name "Vinland"-Erik might have erroneously assumed that he was hallucinating while uttering "Here's Vinland!" -, no such confusion may have ultimately affected Doyle, the author of the "Holmes" tales. Thus, there is no reason of being ultimately skeptical on the genuinely "empty" character of any putatively "empty" referential chain. As a result, there are cases in which (FV) is justified.

Yet also this reply does not seem to be enough. For one may well hold that the real problem with Kripke's justification for (FV) is not an epistemological one. Let us well assume that there are, in Evans (1982)' terminology, existentially creative make-believe games, namely, games in which one makes believe that there is an individual (named in a certain way) that does a lot of things. The "Holmes" tales are precisely cases of such make-believe games: once upon a time, there was an individual named "Holmes" that was a detective, and so on and so forth. Now, Evans distinguishes existentially creative make-believe games from existentially conservative make-believe games, namely, games in which, of a certain already constituted individual, one makes believe that that individual does a lot of things. The "Napoleon" tale in War and Peace is a typical example of an existentially conservative make-believe game: of Napoleon, i.e. of the full-blooded French emperor, Tolstoy makes believe e.g. that he had a certain toilette during his Russian stay. Now, the point is that an existentially creative make-believe game may well be grounded in an existentially conservative make-believe game. As psychoanalysts repeatedly tell us, one such grounding frequently occurs in dreams: a creative dream, such as a dream in which one fantasizes that a fascinating woman happens to rape him, may well turn out to be a 
conservative dream of one's mother disguised as such a woman. Yet the same often happens with hallucinations and illusions. As Donnellan (1966, p. 296) once made clear, cases in which one simply hallucinates that e.g. that man over there has a walking stick while over there is absolutely nothing are rather rare; the most typical case is the illusory situation when one mistakes, say, a rock as a man and thinks that that man-which actually is a rock - has a walking stick. Thus, in such a case of a rock one has illusorily thought that it had a walking stick. So, no wonder that one such grounding also happens in purely make-believe games. To borrow an example from Walton (1990), in making believe that there is a bear grudgingly approaching, one ends up with making believe of a stump that it is so approaching. Thus again, cannot be the case that an indisputably "empty" referential chain is ultimately grounded in a "full" referential chain? And if this is the case, does not this leave (FV) without a real justification?

A caveat. The problem I just raised for (FV) is completely independent of the semantic account we give of sentences involved in existentially creative make-believe games. Let me explain.

As I have hitherto put it, from the linguistic point of view the distinction between existentially creative and existentially creative make-believe games seems to trace back to a well known distinction between a de dicto and a de re reading of a sentence involving an intensional operator, a make-believe, or pretense, operator in such a case. Like any other sentence involving one such operator, a sentence of the form "S pretends that a is F" may be read either de dicto, as: "S pretends that: a is F" or de re, as: "of a, $S$ pretends that it is F". If this were the case, the problem raised by the present opponent of (FV) would simply be the old Quinean one according to which in order for a de dicto reading of one such sentence to be true, some de re reading or other of that sentence must be true as well (cf. Quine, 1971, p. 106).

At this point, a defender of (FV) might simply reply that, once one accepts a directly referential account of proper names, according to which the semantic contribution of a (token of a) name to the truthconditions of the (tokened) sentence in which it figures is exhausted by its referent, the problem no longer occurs. For, once we use an allegedly empty proper name, e.g. "Holmes", in an existentially creative make- 
believe game, for a "direct reference" theorist is hard to accept that this use is accounted for by a de dicto reading of a sentence of the above form, in which a pretense operator occurs: say,

$S$ pretends that: Holmes is a detective.

For if that name is empty, then it simply gives no truth-conditional contribution to a sentence containing it in any reading.

As a matter of fact, it would be hard to circumvent this problem by claiming that in the de dicto reading one such name is synonymous with a definite description, so that the embedded sentence in which that names occurs gives a Russellian, descriptive truth-conditional contribution to the sentence embedding it (in such a reading) ${ }^{2}$. For not only that partial adoption of descriptivism is scarcely justifiable. What would be the justification for claiming that proper names come in two semantical categories, the full ones which are genuine directly referential devices, and the empty ones which are disguised definite descriptions? Moreover, that adoption would implausibly sever semantics from semantic competence. As we just saw before, we often do not recognize either that a proper name is full or that it is empty. So if partial descriptivism held, we would have that we do not often recognize which semantic category a proper name belongs to - the category of a genuine directly referential device or that of a definite description.

To be sure, the intensionalist defender of the de dicto reading of sentences like (3) is not forced to adopt a partial descriptivism. She may opt for a non-descriptivist account of a name like "Holmes" that enables it to be both i) empty and ii) such that the embedded sentence in which it figures still provides a truth-conditional contribution to the sentence embedding it (in its de dicto reading) ${ }^{3}$.

Yet once one wants both to fulfill the above aims i)-ii) and still be non-descriptivist as regards proper names, there is an easier way to do all these things. By following Recanati (2000), one can account for the difference between existentially creative and existentially conservative make-believe games in terms of there being a meaning-relevant vs. a

\footnotetext{
${ }^{2}$ One such proposal can be traced back to Currie (1990).

${ }^{3}$ Perhaps applying to this case the analysis provided by Sainsbury (2009, pp. 36$38)$.
} 
meaning-irrelevant context-shift in the simple sentence at issue containing the name involved in such games. By "context", I here mean a traditional Kaplanian context, namely a certain set of parameters which provides a sentence endowed with a linguistic meaning with determinate truth-conditions. ${ }^{4}$ Thus in the former case, the "Holmes"-case, a "Holmes"- simple sentence, e.g. (1), will express no truth-conditions when linked to a real context having the real world as its "world"parameter in which "Holmes" refers to nothing, but it will have genuine truth-conditions when linked to a pretend context having the world of the Holmes tales as its "world"-parameter in which "Holmes" refers to a concrete individual that is a detective, in conformity with the corresponding existentially creative make-believe game. A meaningrelevant context shift will thus have occurred. In the latter case, the "Napoleon"-case, a "Napoleon"-sentence will express the one and the same truth-conditions both when linked to a real context in which "Napoleon" refers to the French emperor and when linked to a pretend context characterized by an existentially conservative make-believe game in which "Napoleon" again refers to the French emperor. A meaning-irrelevant context shift will thus have occurred.

Granted, if the directly referential approach to proper names is correct, this "context-shift"- account of the difference between existentially creative and existentially conservative make-believe games is better than the above, intensionalist, one, both in the descriptivist and in the nondescriptivist version. Yet unfortunately it does not satisfy the opponent of (FV). For the original problem she raised remains untouched.

Indeed, the opponent of (FV) may simply say the following. Let us accept that the idea that a certain, effectively empty, name makebelievedly refers to something in an existentially creative make-believe game is accounted by saying that there is a pretend context in which that name refers to something. Yet in order for that pretend context to subsist, it must again be grounded in a real context which is such that that very name is not empty, but it really refers to something. Thus

\footnotetext{
${ }^{4} C f$. Kaplan (1989). This context is what people ordinarily labels "narrow context", while Predelli (2005) calls it "index".
} 
again, no justification for the claim that fictional truths are made-up truths has been found yet.

\section{Creationism as the solution to the "grounding"-problem}

As is well known, creationism on fictional entities maintains that fictional characters are mind-dependent entities, i.e. abstract entities that are created in virtue of some lato sensu mental activity, typically the game of make-believe which is originally performed by a story-teller and subsequently shared by its audience. ${ }^{5}$ Creationism comes in different versions; for the time being, let us assume that creationism is correct in some version or other. ${ }^{6}$

Now, if this is the case, then we have found a way to legitimize Kripke's justification for (FV). For, once a fictional individual has been generated, it can still be the case that one erroneously believes she is referring to a concrete real individual while she is referring to that fictum. As a matter of fact, the generation of a fictional entity need not be transparent. This is precisely the case with Santa, or with any other mythological entity: an individual - a child — can think that the individual she is referring to by "Santa" is a concrete real individual, whereas in point of fact she is referring to a mythological character. As we saw before, this is also the case with some properly fictional entity, such as King Arthur. Yet it cannot be the case that by using the name of the fictum which has been generated-"Santa", "Arthur", or even "Holmes" -, one erroneously believes that she is referring to that fictum, whereas in point of fact she is referring to a concrete real individual.

The reason is simple. Once a fictum has been generated, there is no longer a chance that using the name involved in that generation"Holmes", let us suppose -makes its user an unaware member of an

\footnotetext{
5 See Predelli (1997, 2002), Salmon (1998), Schiffer (1996, 2003), Thomasson (1999, 2003a, b).

${ }^{6}$ On the different versions of creationism, see my Voltolini (2009). We will immediately see that only versions of creationism that accept that sentences like (1) are true in their characterizing use are the relevant ones. For clearly, a creationism that does not accept that cannot support (FV).
} 
already preexisting "full" referential chain for that name leading back to a concrete real individual. As we saw, this was the risk involved in using the name within an existentially creative make-believe game. Yet for a creationist one must distinguish this pretending use of that name, in which one merely make-believedly refers to an individual but in point of fact she is referring to nothing, from other uses of that name, in which she is referring to a fictional entity. First of all, the hypostatizing use, the use in which one refers to that entity by characterizing it via features external to the fictions which involve it-paradigmatically, the use we typically make of:

$$
\text { Holmes is a fictional character. }
$$

But also the characterizing use, the use in which one refers to a fictional entity by characterizing it via features internal to the fictions which involve it - paradigmatically, the use we make of (1) when we are not engaged in a make-believe game with it. ${ }^{7}$ Now, these latter uses linguistically support the generation of a fictum. Thus, by means of them a new "full" referential chain for the name involved has been settled. So, there is no chance that by so using the name one slides back into an already pre-existing "full" referential chain for that name leading back to a concrete real individual. As instead could be the case with the pretending use of sentences like (1): in such a case, the "empty" referential chain regarding "Holmes" may always turn out to be grounded in a "full" referential chain for that name involving a concrete real individual. Thus, Kripke's idea that the fiction-involving name "Holmes" does not refer to any concrete real individual is now vindicated. Hence, his justification of (FV) is legitimate.

The idea that one needs not only realism on fictional entities but specifically creationism on such entities will strike many as surprising. How can it be that we need such a position in order to justify the idea, to put it in a nutshell, that there is a gap between fiction and (outer) reality?

But the point is that in order to have fictional truths as a specific kind of truths - to repeat, truths which are such for they are stipulated to be true-we precisely need to tell the pretending use from the

\footnotetext{
${ }^{7}$ For the difference between the pretending and the hypostatizing use, $c f$. Schiffer (1996, 2003); on the characterizing use, $c f$. Barbero (2005).
} 
characterizing use of fiction-involving sentences. For if sentences in the pretending use may be deemed as true, this is because they are true with respect to a make-believe world, namely a world in which things go precisely the way in which the relevant story-teller pretends that they are. This can clearly be seen if we adopt a "context-shift" approach to sentences in that use. Insofar as for a sentence to be pretendingly used, say (1), amounts for it to be linked with a pretend context whose "world" parameter is represented by the relevant world of make-believe, that sentence in such a context is true with respect to that world, the world of that context, iff the concrete individual named "Holmes" is a detective in that world. So, sentences in that use are not true because they are stipulated as such, but because things go in a particular way in the world that use points to. Yet once we pass to the characterizing use of a sentence, say (1) again, there is no explanation for the fact that a sentence in that use is true but to appeal to the idea that this is how the story-viz., a certain set of propositions - goes: in our case, to the idea that the proposition that the fictional character Holmes is a detective figures within the proposition set that constitutes the Holmes stories. ${ }^{8}$ Of course, the story might have gone differently, if simply Doyle had so decided; in such a case, another sentence in the characterizing use would be true insofar as the corresponding proposition would figure in the different propositional set which would then constitute the Holmes stories. ${ }^{9}$

\footnotetext{
${ }^{8}$ By "story" I intentionally mean something different from what I meant by "tale" before. For I distinguish between fictional tales, which are made by pretendingly used sentences, and fictional stories, which are made by the propositions expressed by characterizingly used sentences. For more on this distinction, $c f$. my Voltolini (2006, 2009).

${ }^{9}$ Incidentally, there would no improvement if an antirealist accepted that there is a characterizing use of sentences like (1) but adopted an intensionalist account of that use, by saying that in such a use a sentence like (1) is ellyptical for a sentence of the form "in the Doyle's stories, Holmes is a detective" in its de dicto reading. For even in that case, a sentence containing an intensional operator would be true iff its embedded sentence were true in an unreal world. Thus in the case of a de dicto reading of the former sentence, the sentence in that reading would be true either descriptivistically, i.e. iff the denotation of the embedded singular term in the unreal world had in that world the property expressed by the embedded predicate $-c f$.
} 
Now, this distinction between a pretending and a characterizing use of fiction-involving sentences is typical of any good creationist position on fictional entities. For a creationist who limits herself to acknowledging the pretending and the hypostatizing use of a fiction-involving sentence will owe us an extra-justification as to why we have to accept fictional entities in our general inventory of what there is. ${ }^{10}$ In other terms, if we had to admit ficta only because we have a hypostatizing use of certain sentences, it would be better to buy an antirealist paraphrase of that use. ${ }^{11}$ Thus, my original claim may be refined as follows. If one endorses a good creationism on fictional entities, i.e. a creationism which allows for a distinction between the pretending and the characterizing use of fiction-involving sentences, one may ground Kripke's reason for accepting (FV), hence one may ground (FV) as well. As Kripke (1973) seems to endorse creationism as well along with that distinction, this should be for him a welcome result.

\section{A metaphysico-ontological comment}

As we have seen, (FV) can be ultimately justified by appealing to (good) creationism on fictional entities. That is, sticking to (FV) requires (good) creationism on ficta. This may also be seen as an argument in favour of a metaphysically moderate ontological realism on ficta, as (good) creationism is.

Let me adhere to a distinction between metaphysics, as the doctrine which studies the nature of given kinds of things, provided that there are any, and ontology, as the doctrine which studies whether in the general

Lewis (1979) — or non-descriptivistically, i.e. iff the embedded sentence, as uttered within a fictional context hence when pretendingly used, were true in the world of that context $— c f$. Walton (1990). As a result, in either case the idea that a sentence in a characterizing use is true stipulatively would simply vanish.

${ }^{10} \mathrm{I}$ am unsure as to who, among the traditional creationists, may be ranked within the bad ones. Possibly inspired on this concern by Schiffer $(1996,2003)$ Thomasson (2003a, b) seems to give up her previous (1999) idea that in what I take to be characterizingly used sentences names like "Holmes" refer to ficta.

${ }^{11}$ I stressed this point in my Voltolini $(2006,2009)$. 
inventory of what there is there really are things of a certain kind. ${ }^{12}$ Armed with this distinction, on the one hand I may say that from the ontological point of view we need to be realists if we want to stick to (FV). For limiting oneself to accepting the pretending use of fictioninvolving sentences, as an antirealist often does, ${ }^{13}$ leaves (FV) as an arbitrary principle, insofar as that use is unable to justify it ${ }^{14}$. Yet on the other hand, from the metaphysical point of view, we don't need a radical realism, according to which ficta are mind-independent things, for instance some kinds of Platonistic entities (sets or properties, Platonic attributes $)^{15}$, or inhabitants of worlds different from the actual one. ${ }^{16}$ For a radical realist does not acknowledge the pretending use of fictioninvolving sentences, by assimilating such a use to the characterizing use. By so doing, however, she simply fails to see the problem affecting (FV) as a genuine problem, which is a too dogmatic way of putting things. Now, in conceiving ficta as mind-dependent entities, (good) creationism is a metaphysically moderate form of realism. Since its avoiding the Scylla of antirealism and the Charybdis of radical realism allows (good) creationism to account for the problem raised to (FV) at the same time, the metaphysically moderate ontological realism that (good) creationism constitutes seems to be the best position on fictional entities.

\footnotetext{
${ }^{12}$ For this distinction, $c f$. e.g. Thomasson (1999).

${ }^{13}$ Or even reducing the hypostatizing use to a form of pretending use, as inveterate antirealists do. Cf. Walton (1990).

${ }^{14}$ This would also be the case if the antirealist accepted that there is a characterizing use of fiction-involving sentences but she claimed that such a use may be accounted for in intensionalist terms. $C f$. fn. 9 above.

${ }^{15} C f$. Parsons (1980) for the first and Zalta (1983) for the second alternative.

${ }^{16} C f$. again Lewis (1978) for "a variable domain"- and Priest (2005) for "a fixed domain"- conception of this variant of radical realism.
} 